\title{
Regulation and decision-making in environmental radiation protection
}

\author{
C.-M. Larsson \\ Swedish Radiation Protection Authority, 17116 Stockholm, Sweden
}

\begin{abstract}
The EC-funded project FASSET (Framework for ASSessment of Environmental impacT), which completed in 2003/2004, has developed an assessment framework for evaluating the environmental impact of ionising radiation on biota in natural ecosystems. The framework provides practical and scientific support to the international development of recommendations for radiological protection of the environment through the International Commission on Radiological Protection [1]. However, on the basis of experiences from FASSET and other recent developments, it can be concluded that there are challenges remaining before environmental radiological protection can be seen as a natural component of general environmental protection. The major future challenge is the development of an integrated approach where decision-making can be guided by sound scientific judgements. This requires, inter alia, filling basic knowledge gaps relevant to assessment and protection, through targeted experimental, theoretical (including expert judgements) and real case studies; development of risk characterisation methodologies, based on both theoretical and experimental studies; development of screening standards, where appropriate; development of user-friendly assessment tools; and stakeholder involvement, supported by targeted communication strategies. A new EC-funded project, ERICA (Environmental Risk from Ionising Contaminants: Assessment and management), has recently started aimed at some of these issues. The project has four operational work packages, being devoted to the development of practical assessment tools (WP1), risk characterisation (WP2), decision-making involving stakeholder dialogue (WP3) and cases studies (WP4). The implications of the FASSET project and its contribution to prioritisation within ERICA are discussed.
\end{abstract}

\section{INTRODUCTION}

While a large amount of effort has been directed recently to the development of frameworks for assessing the effects of ionising radiation on the environment, relatively little has been done in terms of developing regulatory guidance or guidance directed to decision making relevant to the environmental effects of radiation. However, with the publication of ICRP Publication 91 [1], a major step towards consensus in this area was taken, although it remains to be seen what impact this will have on the radiation protection community in terms of the new recommendations from the ICRP, due 2005, and subsequent guidance documents developed with the new recommendations as a basis.

The system proposed by ICRP, which has been scientifically underpinned by, e.g. the FASSET project (Framework for Assessment of Environmental Impact, funded under the EC $5^{\text {th }}$ Framework Programme) and the guidance developed by the UK Environment Agency [2], focuses on biota, and uses estimates of exposure and dose, and resulting effects, to a limited number of reference animals and plants (RAPs) as a basis for the impact assessment. The RAP is an organism with defined characteristics in terms of size, feeding habits, reproduction, etc., that serves as a reference in the assessments - very much like the reference man used in human radiological protection.

The concept of RAP appears unanimously accepted in the general sense, i.e. that assessments have to be targeted at some sort of biological entity that can subsequently form the basis for assessing (potential) impact, and for decisions. While there is thus agreement on the purpose of a RAP, the way 
they are identified may differ, partly depending on what kind of guidance the assessment is supposed to provide, and how it relates to public perceptions and values. It now seems timely to explore how the connection between assessment and decision-making could be set up. This communication considers some aspects on this subject, highlighting the new ERICA project (Environmental Risks from Ionising Contaminants: Assessment and Management), pursued under the EC $6^{\text {th }}$ Framework Programme.

\section{DECISION-MAKING IN ENVIRONMENTAL ISSUES}

\subsection{The 'regulatory and decision-making cycle'}

As part of the development of the FASSET Framework, 20 'systems' for environmental assessment and management of ionising contaminants and other hazardous agents were analysed in terms of common elements [3]. A generalised scheme was drawn up, for the purpose of the development of the FASSET Framework and incorporating the elements of the analysed systems, as outlined in Figure 1. For any activity, a number of generic stages can be identified, as itemised below and also illustrated in Figure 1.

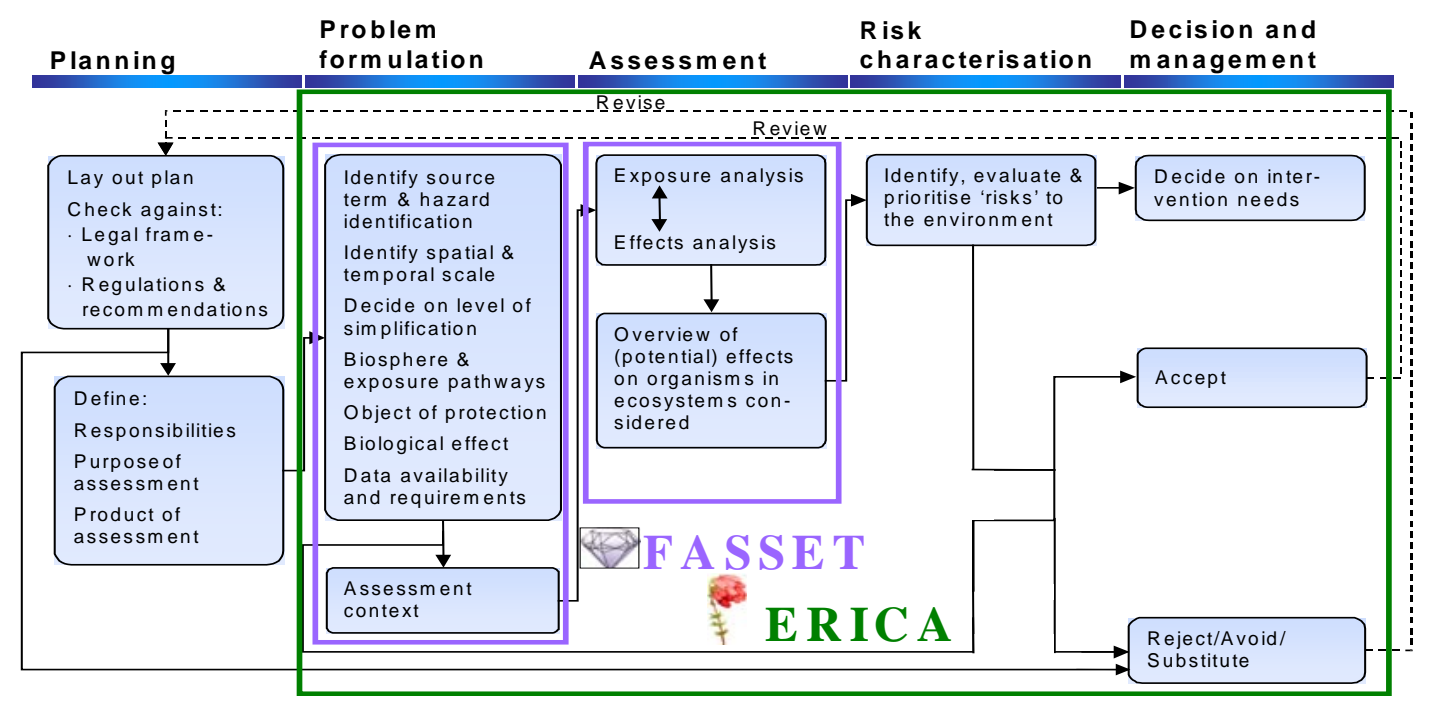

Figure 1. The regulatory and decision-making cycle as described in the FASSET project [3], based on the synthesis of information from 20 pathway-based assessment/management systems for ionising contaminants and hazardous substances. Included in the illustration are also the remits of the FASSET and ERICA projects.

\subsubsection{Planning}

It is obvious that any plan for a project or major activity (including intervention) needs to be checked against the legal framework and existing regulations and recommendations. Any failure to do so may result in plans being rejected on the basis of being non-compliant, or on the basis of lack in public confidence as solicited in stakeholder dialogues. Provided that the initial screening against legal questions and public perceptions does not call for rejection or revision, further consideration is required concerning the division of responsibilities (normally defined in legislation), purpose of further assessment, and product of further assessment. Normally, the final product would be an Environmental Impact Statement (EIS), where radiological consequences are one out of many environmental consequences to be considered. 


\subsubsection{Problem formulation}

Provided that the purpose and product of further assessment have been defined, the problem formulation step is carried out in order to formulate the context for the assessment. For the purpose of FASSET, the essential parts have been identified as:

- identification of source term and initial hazard analysis;

- identification of the spatial and temporal scale;

- decision on the appropriate level of simplification;

- identification of 'biosphere' system and exposure pathways to be considered;

- consideration of what biological effect objects of protection in the environment that need to be considered; and

- consideration of data availability and data requirements.

It needs to be clearly pointed out that the process of formulation of the assessment context may actually lead to the rejection of a proposed concept, on the grounds that:

- the mere presence of a hazardous substance in the environment could be deemed unjustifiable and any activity leading to the presence of such substances should be rejected, avoided or substituted; or that

- there is reasonable support for the view that a substance released into the environment can lead to harmful effects, although there is lack of full scientific proof of such effects. The application of cost-effective measures to reduce, or eliminate, releases of such substances is referred to as the precautionary principle. However, such decisions may be reverted if further analysis reveals that the resulting risks are negligible or possible to manage.

\subsubsection{Assessment, risk characterisation, and decision and management}

The assessment steps involve the analysis of dispersion and exposure through different exposure pathways to specified biological endpoints, as well as an account of effects. The assessment results in an overview of potential effects in biota considered in the assessment.

In risk characterisation, a full review of actual or potential effects is carried out in order to prioritise and to define what we really need to be concerned with, which will guide the necessary managerial steps as well as discussions on intervention. The subsequent decisions and managerial actions involve evaluation of intervention needs, decisions on licensing conditions and acceptance of a proposed concept (when appropriate), and possibly the rejection, avoidance or substitution of a certain activity. As also indicated in Figure 1, a decision of acceptance normally requires recurrent reviews; a decision to reject/avoid/ substitute can be reversed by revision of concept and renewed assessment. One particular example of the latter is the use of tiered approaches, where a low-tier conservative and simple assessment can be replaced by more complex, realistic and non-conservative assessments, if $e . g$. derived standards are exceeded in the initial, low-tier assessment.

The public's view in this decision-making process is sought through public consultation procedures that can be arranged in different ways. It is important to bring early on the views of different 'stake-holders' as these may shape the assessment context.

\subsection{From FASSET to ERICA - consideration of risk characterisation and management}

On the basis of experiences from FASSET, and other recent projects, it can be concluded that:

- there is substantial agreement in terms of conceptual approaches between different frameworks currently in use or proposed; and

- differences in technical approaches can largely be attributed to the differences between ecosystems of concern, or to different national legal requirements. 
The major future challenge now seems to be the development of an integrated approach where decision-making can be guided by sound scientific judgements. This requires, inter alia:

- filling of gaps in basic knowledge of relevance to assessment and protection, through targeted experimental, theoretical (including expert judgements) and real case studies;

- development of user-friendly assessment tools;

- development of risk characterisation methodologies, based on both theoretical and experimental studies and incorporating a rationale for extrapolation of effects data;

- development of screening standards, where appropriate; and

- stakeholder involvement, supported by communication strategies.

Some of these outstanding issues will be addressed within the ERICA Project. Figure 1 illustrates how the ERICA project extends from the problem formulation and assessment stages (considered within FASSET) to also incorporate risk characterisation and decision-making.

\section{ERICA - ENVIRONMENTAL RISKS FROM IONISING CONTAMINANTS: ASSESSMENT AND MANAGEMENT}

The objective of ERICA is to provide an integrated approach to scientific, managerial and societal issues concerned with the environmental effects of contaminants emitting ionising radiation, with emphasis on biota and ecosystems. The objective will be fulfilled through the development of a user-friendly assessment tool with risk characterisation methodologies coupled with communication strategies aimed at decision-making. This involves detailed consideration of gaps in scientific data, expansion of the current FASSET effects database, and experimental and theoretical considerations of extrapolation issues, e.g. from effects on individuals to effects on populations. The tool will be tested and applied to a series of case studies. The development of science-based managerial guidance, including methodologies for stakeholder involvement in assessments, will be based on a number of meetings with end-users representing a range of different interests (the 'End-Users Group', EUG), whom have agreed to participate in ERICA.

The project started in March 2004 and is to end by February 2007. The organisation of the project in separate work packages, and their interaction to deliver the ERICA Integrated Approach is schematically illustrated in Figure 2. In this section, ongoing work within the four operational work packages will be described, whereas work package 5 is concerned mainly with the project's management and its internal progress review. The progress of the project can be followed on its website, www.erica-project.org.

\subsection{The development of a user-friendly assessment tool (work package 1)}

This aspect of the ERICA project develops further the assessment methodology delivered by FASSET. This involves broadening the database on environmental radionuclide transfer and dose conversion coefficients. Furthermore, the existing FASSET Radiation Effects Database [4] will be updated with new data, taking into consideration data being from sources previously not considered, to build a new "FREDERICA" database. Actions to accomplish this include: a merging of the FRED database with the EPIC database (built up under the EC $5^{\text {th }}$ Framework Programme project Environmental Risks from Ionising Contaminants in the Arctic), insertion of data from post 2001 articles; inclusion of a limited number of specific experimental data, which will be carried out within the ERICA project; and a new output structure for the ERICA database providing more flexible search options.

The assessment tool developed under this work package will integrate environmental radionuclide transport, bioaccumulation, dosimetry, and radiation-effect assessment in a comprehensive, flexible and user-friendly manner. Commonly available Windows software supplemented by the modelling software package Ecolego [5] will be used as a basis for development of the tool. 


\subsection{Risk characterisation (work package 2)}

The risk characterisation step within the framework of an environmental risk assessment (ERA) synthesises the information gained during the assessment, puts it in relation to other hazards associated with the source in question, and also forms the basis for prioritisation of risks and, consequently, for the decisions on actions (management). Such actions may be driven by formal regulations or be subject to scrutiny by interested parties ('stakeholders') before the decision on action is taken. The way the risk characterisation is carried out is, therefore, often highly influenced by regulatory criteria and standards, as well as by public perception and societal views on what is acceptable. In this way, the risk characterisation forms the bridge between the assessment of radiation effects, and the management of these radiation effects in terms of decisions on, e.g. acceptance/rejection of proposed plans, discharge control, interventions.

The risk characterisation may also involve the derivation, and application, of certain numerical criteria to define 'what is safe' or 'acceptable risk'. It seems that few innovative studies aimed at the derivation of such criteria have been performed in recent years within the radiation field. Most systems [6,7], currently employing such numerical criteria (normally for screening purposes), fall back on the 1992 IAEA Tecdoc 332 [8], which never intended for setting regulatory criteria, although there are exceptions [9].

In relation to risk characterisation, ICRP is developing the approach of derived consideration levels, in which the magnitude of concern is related to background radiation (or concentration) levels, using a scale of insignificant to major concern as an indicator and guidance for decision-making. Clearly, this is an area where major steps forward can be made in the field of environmental radiation protection, possibly aided by harmonisation with approaches used for other contaminants. Work package 2 will thus consider risk characterisation methodologies as used across a wide range of environmental issues, as well as extrapolation issues including supporting experimentation, aimed at the development of good practise guidance for risk characterisation.

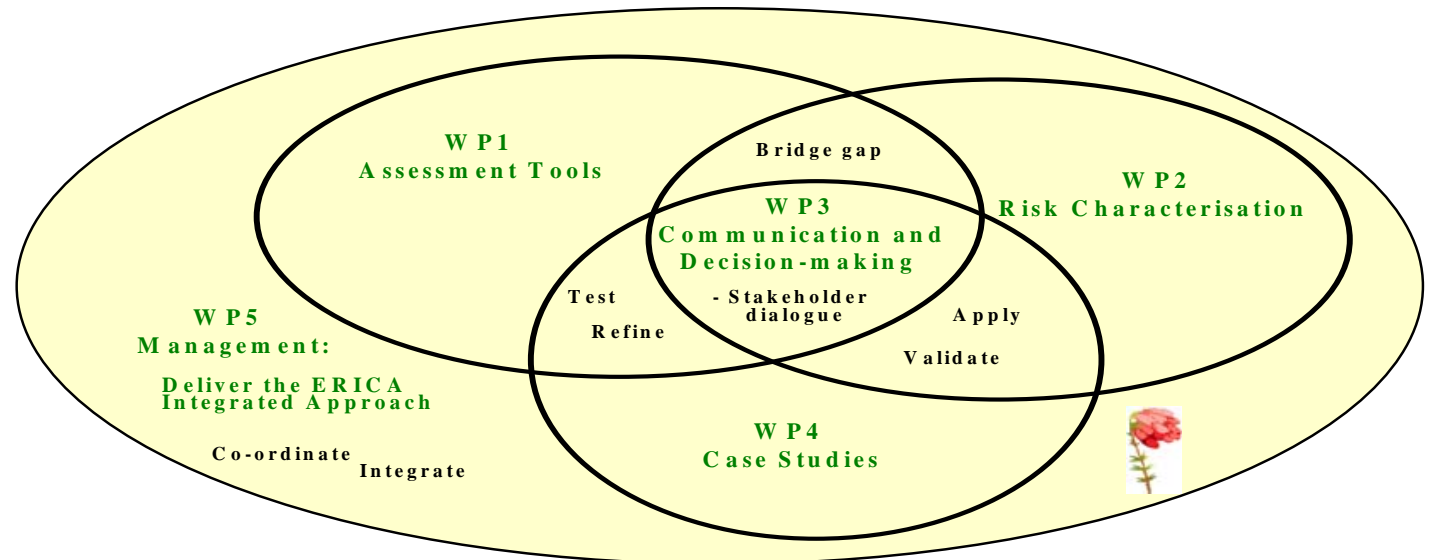

Figure 2. The organisation of the ERICA project, and interaction between the work packages (WP) to deliver the ERICA Integrated Approach.

\subsection{Communication (work package 3)}

The task of this work package is to develop managerial guidance supported by stakeholder involvement in order to protect the environment from harmful effects of ionising radiation. The activities of this work package can be grouped into three broad categories:

- $\quad$ to set up and consolidate the End-Users Group, EUG;

- $\quad$ to perform a number of consultation activities involving the EUG; and

- develop guidance and perform training. 
EUG consultations will focus on: identification of key information needs for setting criteria and standards; reaching consensus in areas of significant scientific uncertainties; management, demonstration and compliance; and, as a special case, a dialogue involving local stakeholders in the UK case study. Towards the end of the project, a workshop will be organised to demonstrate to end-users how the assessment system developed within the framework can be practically applied.

The EUG represents a wide range of interest in this area, and includes representatives of governmental agencies, inter-governmental organisations, academia, NGOs, industry and independent experts. As of August 2004, the EUG consists of 44 members, centred in Europe but also with membership from Canada, USA and Australia. The EUG is currently 'consolidated but not locked' - this means that additions can still be made in case there are strong arguments to do so. The results of the first two EUG events have been posted on the project's website [10].

\subsection{Case studies - application of FASSET and ERICA methodologies (work package 4)}

The task of this part of the project is to test and improve methodologies in practical case studies, to facilitate the development of the ERICA integrated approach. A variety of sites with different discharge histories (routine anthropogenic, accidental anthropogenic, technologically-enhanced natural) and ecosystems have been selected.

- Sellafield (UK) - Routine aerial and marine releases from Sellafield have resulted in estuarine and terrestrial contamination with a wide range of different radionuclides to comparatively high levels.

- Loire River (France) - The Loire River receives routine discharges from nuclear power plants. This case study provides the opportunity to test the freshwater and brackish components of FASSET/ERICA.

- The Chernobyl exclusion zone (Ukraine) - The zone provides a site where radiation-induced effects have been observed for anthropogenic sources, enabling effect predictions to be assessed.

- Oil rigs (North-East Atlantic) - Estimates of input of radioactive substances into the marine environment suggest that the European offshore oil industry is a significant source of alpha-emitting radionuclides.

- Komi Republic (Russia) - This is an area of high natural radioactivity where radiation induced effects have been reported.

\section{CONCLUDING REMARKS}

Building of assessment frameworks for environmental radiation, that are similar to those used for other hazardous substances, facilitates communication and exchange of experience across broad areas of environmental issues. However, relatively little has happened so far in terms of international policy development. The rate by which environmental radiation may become part of policies depends to some extent on how the ICRP will integrate the content of Publication 91 into its forthcoming general recommendations, due 2005. The ERICA project, as well as other recent and ongoing activities, may further support policy development by supplying underpinning scientific knowledge, assessment frameworks and tools, as well as decision-making guidance.

\section{Acknowledgements}

This work was supported by the EC-EURATOM 6 Framework Programme (2002-2006) and forms part of the ERICA (Environmental Risk from Ionising Contaminants: Assessment and Management) project, contract FI6R-CT-2003-508847. The financial support of the EC is gratefully acknowledged. 


\section{References}

[1] International Commission on Radiological Protection, Publication 91, Ann. ICRP 33 (2003).

[2] Copplestone D, Beilby S, Jones S R, Patton D, Daniel P and Gize I, Impact assessment of ionizing radiation on wildlife, Environment Agency, UK (2001) ISBN 185705590 X.

[3] Larsson C-M and Jones C, editors, FASSET Deliverable 2 Part 1, Formulating the FASSET Assessment Context; Part 2, Overview of programmes for the assessment of risks to the environment from ionising radiation and hazardous chemicals (2002), www.erica-project.org

[4] Woodhead D and Zinger I, editors, FASSET Deliverable 4, Radiation effects on plants and animals; FASSET radiation effects database, FRED (2003), www.erica-project.org

[5] Avila R, Broed R and Pereira A, Ecolego - a toolbox for radiological risk assessment. In: International Conference on the Protection of the Environment from the effects of Ionizing Radiation, Stockholm, IAEA-CN-109 (2003), pp. 229-232.

[6] Environment Agency, Assessment of radioactive discharge screening levels for biota protected under the Habitats regulations. National Compliance Assessment Service Technical Report NCAS/TR/2001/019, Environment Agency, UK (2002).

[7] Higley K A, Kocher D C, Domotor S L, Bilyard G R, Antonio E J, Jones D S and Sample B E, Derivation and application of a screening methodology for evaluating radiation doses to aquatic and terrestrial biota, Proc. 2nd Int. Symp. Ionizing Radiation: Environmental Protection Approaches for Nuclear Facilities, Ottawa, 1999 (Atomic Energy Control Board/Canadian Nuclear Safety Commission (2001) pp. 58 - 68.

[8] International Atomic Energy Agency, Effects of ionising radiation on plants and animals at levels implied by current radiation protection standards, Technical Report 332, IAEA, Vienna (1992).

[9] Thompson P and Chamney L, Environmental protection program to be implemented to fulfil the mandate of the new Canadian Nuclear Safety Commission Proc. 2nd Int. Symp. Ionizing Radiation: Environmental Protection Approaches for Nuclear Facilities, Ottawa, 1999, Atomic Energy Control Board/Canadian Nuclear Safety Commission (2001), 131 - 135.

[10] Oughton D, Zinger I, Bay I, Borretzen P, Garnier-Laplace J, Larsson C-M, Howard B, ERICA Deliverable 7a, Part1, Discussion of ERICA workplan; Part 2, Briefing notes on assessment frameworks and knowledge gaps, (2004), www.erica-project.org 